DOI: $10.12731 / 2306-1561-2013-4-13$

\title{
DEVELOPMENT OF AN INTEGRATED DOCUMENT MANAGEMENT SYSTEM: THE INTERACTION OF DATABASE PRODUCTS AND ARCHIVE DOCUMENTS
}

\author{
Obukhov A.D., Krasnianskiy M.N.
}

\begin{abstract}
Design, production and sale of products industry is impossible without a huge amount of documentation, and there is a need of using modern means of information for the elimination of paper documents and transition to the automated information system of electronic document circulation. In article are considered questions of complex systems of electronic document circulation in the interaction with the information system of the filing of the company's products. Basic tasks of similar systems, including the provision of quick access to information, storage and protection of documents, the control of documents etc mathematical model of the file based on the presentation of the project in the form of a graph. Tasked with optimizing the formation of project based on the solution of the traveling salesman problem. Considered the effect of joint use of a card file of articles and content management systems within the enterprise.
\end{abstract}

Keywords: document management, electronic document filing, document management, automated system.

\section{УДК 004.8:681.3}

\section{РАЗРАБОТКА КОМПЛЕКСНОЙ СИСТЕМЫ УПРАВЛЕНИЯ ДОКУМЕНТООБОРОТОМ: ВЗАИМОДЕЙСТВИЕ БАЗЫ ДАННЫХ ИЗДЕЛИЙ И АРХИВА ДОКУМЕНТАЦИИ}

\section{Обухов А.Д., Краснянский М.Н.}

\section{Аннотация}

Проектирование, производство и реализация изделий промышленности невозможно без огромного количества сопроводительной документации, в связи с чем появляется необходимость в использовании современных информационных средств для ликвидации бумажного документооборота и перехода на автоматизированнье информационные системы электронного документооборота. В статье рассмотрень вопросы построения комплексных систем электронного документооборота при взаимодействии с информационной системь картотеки изделий предприятия. Сформулированы основные задачи, ремаемые подобными системами, включая обеспечение быстрого доступа к информащии, хранение и защита документов, контролирование движения документащии и т.n. Разработана математическая 
модель картотеки, основанная на представление проекта в виде графа. Поставлена задача оптимизачии формирования проекта на основе решения задачи коммивояжера. Рассмотрен эффект совместного использования картотеки изделий и системы документооборота в рамках предприятия.

Ключевые слова: документооборот, электронная картотека, управление документацией, автоматизированная система.

Проектирование, производство и реализация изделий промышленности невозможно без огромного количества сопроводительной документации: проекты и технические задания, отчеты и заказы, патенты и ГОСТы и др. Надежное хранение и быстрый доступ к этим документам гарантируют стабильность работы предприятия. При этом у традиционного бумажного документооборота достаточно много недостатков. В связи с чем появляется необходимость в использовании современных информационных средств для ликвидации бумажного документооборота и перехода на автоматизированные информационные системы электронного документооборота (СЭД).

Внедрение такой системы призвано решить основные проблемы бумажной документации: потери документов, долгий поиск информации, большие площади для хранения, низкая скорость редактирования и др. [1].

Целью данной статьи является исследование взаимодействия системы электронного документооборота с картотекой производимых изделий.

Хранение документов без связи с текущими актуальными заказами или проектами не имеет смысла, с такой задачей справится любое сетевое хранилище. Наибольший интерес представляет синтез СЭД и картотеки изделий.

Для начала рассмотрим системы по отдельности. Переход на электронный документооборот позволяет решить множество «скрытых» проблем производства, что повышает производительность всего предприятия. Основные задачи, решаемые СЭД, состоят в следующем:

Быстрый доступ к информации с компьютера или планшета, вне зависимости от территориального расположения, получение всегда актуальных данных.

Уведомление сотрудников о поступивших документах, контроль выполнения поставленных задач.

Обеспечение прозрачности при движении документов внутри организации между отделами и сотрудниками (дата изменения; лицо, изменившее документ; внутренняя цифровая подпись).

Реализация электронного архива документов, в том числе - патентов, чертежей, моделей, ГОСТов, проектов.

Выдача шаблонов, разработка электронных форм для облегчения заполнения типовых документов (заявление, распоряжение, приказ и т.д.).

Реализация на основе шифрования ГОСТ системы внутренней защиты документов от несанкционированного редактирования и просмотра. 
Реализация поиска по архиву, выдача результатов в зависимости от прав пользователя (руководитель, начальник отдела, инженер и т.д.) и места его работы (наименование структурного подразделения), оценка ошибок и наиболее популярных запросов.

Практическая ценность внедрения подобной системы заключается в следующем:

- Сокращение временных затрат на поиск и заполнение документации.

- Безопасность хранения документов: вся документация оцифрована, собрана на сервере, имеются резервные копии.

- Возможность получения точной информации об авторе документа и всех лицах, работающих с ним и изменяющих его, с указанием сроков создания документа и датах редактирования.

- Возможность исключения, как полного, так и частичного, бумажной документации из внутреннего оборота предприятия и переход на электронный вариант архива. Следствием этого станет снижение издержек на управление потоками документов организации.

- Повышение ответственности отделов и каждого сотрудника, в частности, за счет прозрачности движения и работы с документацией, возможность оценки качества работы сотрудников.

Рассмотрим более подробно картотеку изделий. Для предприятия, например, химической промышленности, большинство документов основывается на глобальном каталоге всех изделий, деталей, материалов, инструментов и т.п. Требуется создать такую автоматизированную систему, в которой пользователь имел бы возможность редактировать записи, производить поиск по базе данных, формировать заказы путем набора группы записей из базы и извлечения из них необходимой информации (стоимость, структура, физические и экономические характеристики). Для формирования подобной структуры информационной системы и связанной с ней базы данных на основе картотеки изделий требуется построить математическую модель.[2, $3,4]$.

На первом этапе разработки модели формируется граф узлов картотеки. Для примера рассмотрим структуру из множеств деталей, сборок и изделий, совокупность которых формирует конечный проект. При этом сборка и изделие являются узлами одного уровня и могут входить в состав друг друга, а детали - это конечные элементы, на основе которых формируется сборка или изделие.

Введем следующие обозначения:

$P$ - проектный документ; $p_{1}, p_{2} \cdots$ - множество всех изделий; $s_{1}, s_{2} \cdots$ - множество всех сборок; $d_{1}, d_{2} \ldots$ - множество всех деталей.

Тогда проект можно представить в виде графа $P=[W, M]$, 


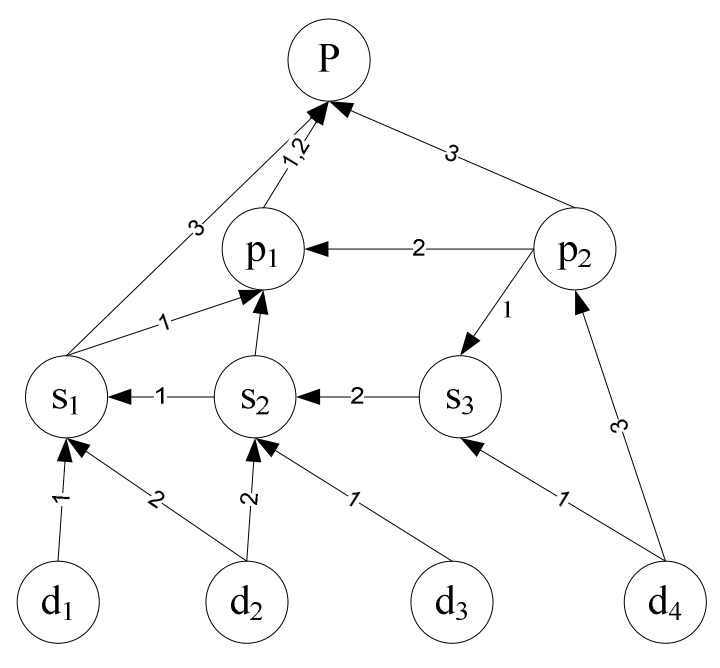

Рисунок 1. Представление проекта в виде графа

где $W_{-}\left\{d_{1} \ldots, d_{n}, s_{1} \ldots, s_{m}, p_{1} \ldots, p_{k}\right\}_{\text {(множество вершин); }}$

$M$ - множество ориентированных дуг, образованных парами $\left(w_{i}, w_{j}\right)$, которые являются элементами множества $W$.[5].

Изделия, сборки и детали могут включаться друг в друга по следующим правилам:

Только выход - детали.

Вход и выход - узлы, которые чаще всего представлены сборками, но на более высоких уровнях могут являться и изделиями.

Только входы - проект, который является конечным изделием.

Ребра графа пронумеруем, обозначив возможные пути формирования проекта. Как видно из рисунка 1, проект может быть составлен различными сочетаниями вершин (указано три пути). Таким образом, с помощью графа мы можем оценивать проект по различным критериям и при необходимости производить оптимизацию, используя взаимозаменяемые компоненты. Для обеспечения наилучшего варианта необходимо найти оптимальный путь.

$$
\text { Пусть } M^{w_{i}, w_{j}}=\left\{w_{i}, w_{j}\right\} \text { - путь от вершины } w_{i} \text { до } w_{j}, \text { a } L\left(M^{w_{i}, w_{j}}\right) \text { - длина }
$$
этого пути, для нахождения которой мы будем ставить в соответствие каждой промежуточной дуге $\left(w_{s}, w_{t}\right)$ некоторый весовой коэффициент $\left(_{w_{s}, w_{t}}-\right.$ применяемость $w_{s}$ вершины в $w_{t}$-ой вершине), определяющий его значимость (стоимость изделия, масса детали, время на изготовление и т.п.). Тогда длина пути от вершины $w_{i}$ до $w_{j}$ равна:

$$
L\left(M^{w_{i}, w_{j}}\right)=\sum_{\forall\left(w_{s}, w_{t}\right) \in M^{w_{i}, w_{j}}}\left(l_{w_{s}, w_{t}}\right)
$$


А полную применяемость узла $w_{i}{ }^{w_{j}}$ будем рассчитывать, как минимум длины пути $M^{w_{i}, w_{j}}$ :

$$
l_{w_{i}, w_{j}}=L_{\min }\left(M^{w_{i}, w_{j}}\right)
$$

Следовательно, применяемость детали $w_{0}$ в проекте определяется как оптимальное положение детали внутри сборок $s_{i}$, изделий $p_{j}$ или в проекте $P$ :

$$
l_{w_{0}, P}=L_{\min }\left(M^{w_{0}, P}\right)=\sum_{s_{i} \in M^{w_{0}, P}} L_{\min }\left(M^{w_{0}, s_{i}}\right)+\sum_{p_{j} \in M^{w_{0}, P}} L_{\min }\left(M^{w_{0}, p_{j}}\right)+L\left(M^{w_{0}, P}\right)
$$

На основе базы данных изделий, сборок, деталей и граничных условий (задаются заказчиком, либо текущими запасами/потребностями предприятия и выражаются в количестве материала/изделий, стоимости, бюджете предприятия, временных интервалах) находятся оптимальные маршруты по графу $P$. В качестве длины ребер выбирается весовой коэффициент. Тогда целевой функцией выступит функция эффективности проекта:

$$
\Phi(P)=\sum_{\forall\left(w_{i}, w_{j}\right) \in P} l_{w_{i}, P}
$$

Результатом вычислений является решение типичной задачи коммивояжера любым известным методом оптимизации, например, методом полного перебора или методом ветвей и границ. В итоге формируется оптимальный набор деталей, сборок и изделий для рассматриваемого заказа [6].

Рассмотрев систему документооборота и автоматизированную картотеку изделий, перейдем к их взаимодействию в рамках предприятия. Картотека изделий очень легко вписывается в комплексную систему электронного документооборота в качестве внешней системы, кроме того, подобная интеграция позволяет повысить ее эффективность за счет возможности не только хранить какие-либо списки компонентов или изделий, но и ссылаться на конкретные документы, чертежи, отчеты, патенты и прочую документацию.

Таким образом, пользователи комбинированной системы получают доступ не только к базе данных изделий, но и ко всем сопутствующим документам (инструкциям, техническим заданиям, справкам и т.д.).

Таким образом, очевидна перспектива использования комбинированных систем документооборота, где хранение и обработка документации органично связаны с реальным производством и бизнес-процессами организации. Подобные СЭД обеспечивают не только надежность и безопасность хранения информации, но и позволяют прямым образом повлиять на качество производства в целом. 


\section{Список информационных источников}

[1] Печникова Т.В., Печникова А.В. Практика работы с документами в организации: учеб. пособие для вузов. - М.: ЭМОС, 1999. - 208c.

[2] Литовка Ю.В., Дьяков И.А., Романенко А.В., Алексеев С.Ю., Попов А.И. Основы проектирования баз данных - Тамбов: ТГТУ, 2005.

[3] Помазанов А.В., Белоусова А.И., Васильева А.О., Остроух А.В. Методика оптимизации баз данных // В мире научных открытий. - 2012. - № 12. - С. 49-54.

[4] Мокрозуб В.Г. Представление структуры изделий в реляционной базе данных // Информационные технологии. - 2008. - № 11. - С. 11-13.

[5] Мубаракзянов Г.М., Дылевский И.В. Математическая теория задач разузлования сборочных единиц // Вестник КГТУ им. А.Н. Туполева. - 2008. - №1. - С.83-86.

[6] Левитин А.В. Алгоритмы. Введение в разработку и анализ / А.В. Левитин - М.: «Вильямс», 2006. - С. 159-160. 